Bol. Mus. Para. Emilio Goeldi. Ciências Naturais, Belém, v. 1, n. 2, p. 37-46, maio-ago. 2006

\title{
Virola surinamensis (Rol. ex Rottb.) Warb. (Myristicaceae): aspectos morfológicos do fruto, semente, germinação e plântula ${ }^{1}$ Virola surinamensis (Rol. ex Rottb.) Warb. (Myristicaceae): morphological aspects of fruit, seed and seedling
}

\author{
Ely Simone Cajueiro Gurgel \\ Ana Cristina Magalhães Carvalho "I \\ João Ubiratan Moreira dos Santos ${ }^{1}$ \\ Marlene Freitas da Silva ${ }^{+}$
}

Resumo: Virola surinamensis (Rol. ex Rottb.) Warb., conhecida popularmente como 'ucuúba', é uma árvore de 40 m de altura, comumente encontrada em lugares alagados, geralmente perto de igapós. Este estudo objetivou descrever a morfologia do fruto, da semente, da germinação e da plântula. Para a descrição, foram retiradas, aleatoriamente, subamostras contendo 30 frutos e 30 sementes. Dos frutos descreveu-se a morfologia geral, a coloração, a textura, a consistência, a deiscência e o indumento do pericarpo. Das sementes analisou-se o tegumento, o endosperma e o embrião. Descreveram-se os principais elementos vegetativos do processo germinativo e das plântulas. Considerou-se germinação o período entre o entumescimento da semente até antes que os eófilos estivessem lançados; e plântula a fase de desenvolvimento em que os eófilos estavam totalmente formados. Toda a descrição foi fundamentada em literatura especializada. A espécie estudada apresenta fruto do tipo folículo, subgloboso, epicarpo opaco, cartáceo, amarelo quando maduro, glabro, com pedúnculo piloso. Semente globosa; com inserção basal livre; arilo laciniado, vermelho, recobrindo toda a semente; testa em tons castanho-escuro, consistência cartácea hidratada e membranosa quando desidratada; rafe linear e homócroma; hilo orbicular e lente imperceptível; embrião micro e endosperma ruminado. Germinação criptocotiledonar epígea. Plântula com eófilos simples, alternos, elípticos, ápice agudo, margem inteira e ciliada, base atenuada, nervação broquidódroma e prefolheação valvar.

Palavras-chave: Manejo florestal. Silvicultura. Identificação de plântula. Amazônia.

Abstract: Virola surinamensis (Roll. ex Rottb.) Warb.. It is well-known popularly as ucuúba, it is a tree of $40 \mathrm{~m}$ of height, usually found in places with swampy flooded, generally close to igapós. This study objectified describes the morphology of the fruit, seed, and kind of germination and of seedling. For the description, they were retired, random sub-samples contend 30 fruits and 30 seeds. Of the fruits were descript the general morphology, coloration, texture, consistency, dehiscence and surface of pericarp. Of the seeds were analyzed the tegument, endosperm and the embryo and described the main vegetative elements of the germination process and seedlings. Considered germination, the period between seed imbibed until before the first eophyll was totally formed; and seedlings the development phase in which eophyll were totally formed. All the description was based in specialized literature. The fruit of the studied species is a follicle, subglobose, epicarp opaque, chartaceous, yellow when mature, glabrous, with pilose peduncle. Seed globose too; with free basal insert; lacinate aril, red, involving all the seed; test in brown-dark tones, dehydrate the consistency is chartaceous and membranaceous when hydrated; raphe lineate and homochromous; hilum orbicular and imperceptible lens; micro embryo, cotyledons shapeless and endosperm ruminated. Cryptocotylar epigeous germination. Seedlings with simple eophyll, alternate, elliptic, apex acute, whole margin and ciliate, attenuated base, brochidodromous enervation and valvate prevernal.

Keywords: Forestry management. Silviculture. Seedlings identification. Amazon.

I Museu Paraense Emilío Goeldi. Coordenação de Botânica. Belém, Pará, Brasil (esgurgel@museu-goeldi.br) (bira@museu-goeldi.br).

II Museu Paraense Emilío Goeldi. Coordenação de Botânica. Bolsista de Desenvolvimento Tecnológico Industrial/CNPq. Belém, Pará, Brasil (anitacarval@yahoo.com.br) (acmagalhães@museu-goeldi.br).

+ In memoriam.

1 Trabalho desenvolvido no âmbito do Projeto Dendrogene (Conservação Genética nas Florestas Manejadas da Amazônia / DFID).

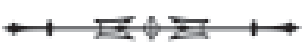


Virola surinamensis (Rol. ex Rottb.) Warb. (Myristicaceae): aspectos morfológicos do fruto, semente, germinação e plântula

\section{INTRODUÇÃO}

O valor dos caracteres morfológicos é avaliado pela constância com que eles se apresentam. Quanto mais constantes, mais confiáveis e mais estáveis são os reprodutivos (LAWRENCE, 1970).

Para compreender melhor o ciclo biológico e a regeneração natural, é necessário um melhor conhecimento da germinação, da unidade de dispersão, do crescimento e do estabelecimento da plântula. Estes aspectos são fundamentais para seu reconhecimento e identificação de plântulas de uma determinada região, dentro de um enfoque ecológico. O tipo de germinação, por exemplo, constitui um dos caracteres relevantes para diferenciar as espécies (DUKE, 1965).

Estudos sobre a auto-ecologia, como a morfologia dos propágulos, do desenvolvimento pós-seminal e de plântulas, também têm aplicações práticas em estudos ecológicos, no manejo florestal e na conservação da fauna autóctone. Na seleção de espécies para enriquecimento da regeneração natural, é indispensável o conhecimento da forma jovem das espécies (OLIVEIRA, 1993).

Sementes e pólen são os principais recursos empregados pela arqueologia e paleobotânica para o conhecimento da vegetação passada, bem como o clima e a agricultura. As sementes, devido ao seu tamanho, constituem material ideal para investigação em microscopia eletrônica de varredura, devido à existência de uma terminologia elaborada para os retículos e outras variações encontradas na superfície das mesmas (STUESSY, 1989; FERREIRA, 1997).

Na Amazônia, poucos trabalhos têm sido desenvolvidos nesta área de conhecimento, os herbários não dispõem de coleção de plântulas de referência e, conseqüentemente, do reconhecimento de um táxon, prejudicando consideravelmente a confiabilidade na identificação de plântulas.

Rodrigues (1980), ao concluir a revisão taxonômica do gênero Virola, alertou para a necessidade de estudos complementares em morfologia externa que permitissem o melhor conhecimento das espécies, visando a subsídios para melhor fundamentar a taxonomia do grupo.

Virola surinamensis é conhecida popularmente como 'ucuúba-da-várzea', 'ucuúba-branca', 'ucuúbaverdadeira', 'ucuúba-amarela', 'árvore-de-sebo', 'bicuiba' e 'virola' (Brasil); 'cumala' e 'caupuri' (Colômbia e Peru) (RODRIGUES, 1972, 1980; LORENZI, 1992; RIBEIRO et al., 1999).

É uma árvore de $40 \mathrm{~m}$ de altura, podendo ser encontrada em florestas tropicais baixas e altas, comum em lugares alagados, geralmente próximos a igapós (RODRIGUES, 1980; LORENZI, 1992). Sua madeira é empregada na fabricação de compensados e, como conseqüência do processo industrial, permite o uso dos resíduos de produção na confecção de papéis tipo Kraft de boa qualidade. Os índices físicos obtidos a partir da madeira são melhores (RODRIGUES, 1972).

Este estudo objetivou descrever e caracterizar a morfologia do fruto, da semente, da germinação e da plântula de V. surinamensis (Rol. ex Rottb.) Warb., a fim de subsidiar o reconhecimento desta espécie nas formações naturais, embasar futuros trabalhos taxonômicos, filogenéticos e ecológicos, preparar duas coleções de referência para plântula, as quais foram registradas nos herbários MG (Museu Paraense Emílio Goeldi, Belém, Pará) e IAN (Embrapa Amazônia Oriental, Belém, Pará).

\section{MATERIAL E MÉTODOS}

Coletaram-se 30 frutos maduros, diretamente da copa e no chão sob a matriz, de um espécime existente no campus de pesquisas da Embrapa Amazônia Oriental, Belém, Pará.

Procedeu-se a coleta de material botânico fértil para confecção de exsicatas e identificação. As exsicatas da planta matriz foram incorporadas aos herbários sob os números: MG 168.267 e IAN 176.904 (Gurgel, E.S.C, 126).

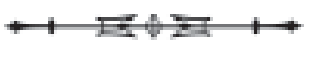


material foi transportado para o laboratório de Botânica da Embrapa Amazônia Oriental, onde os frutos e as sementes foram beneficiados manualmente até a completa limpeza.

Uma amostra com 30 frutos e 30 sementes foi retirada aleatoriamente do espécime coletado, para a descrição morfológica. As características biométricas foram mensuradas com auxílio de paquímetro digital Mitutoyo Digimatic Solar, modelo CD-S1 5M. Com os valores obtidos foram calculados a média, desvio padrão e o coeficiente de variação.

Dos frutos registrou-se a morfologia geral, classificação, coloração, textura, consistência, posição, a deiscência e o indumento do pericarpo. Descreveram-se, das sementes, a forma, consistência, cor e textura do tegumento, posição do hilo e da micrópila, o embrião e o endosperma quanto ao tipo e forma.

Considerou-se germinação o período entre o entumescimento da semente até antes que os eófilos estivessem totalmente formados; e plântula, a fase de desenvolvimento em que os eófilos estavam totalmente formados. A definição de eófilo e metáfilo foi feita com base na análise da planta matriz, considerando-se o conceito de Duke e Polhill (1981). Para o processo germinativo e obtenção da plântula, utilizou-se vermiculita em bandeja de plástico com $80 \times 40 \times 20 \mathrm{~cm}$.

A metodologia e a terminologia empregadas estão de acordo com os trabalhos de Martin (1946), Systematics Association Committee for Descriptive Terminology (1962), Font-Quer (1963), Duke (1965, 1969), Van der Pijl (1982), Radford et al. (1974), Kuniyoshi (1983), Roderjan (1983), Van Roosmalem (1985), Stern (1992), Oliveira (1993), Barroso et al. (1999) e Gurgel (2000).
Os frutos, as sementes e as fases do desenvolvimento, desde a emissão da radícula até a completa formação dos eófilos, foram fotografados. O material vegetativo, relacionado ao processo germinativo e às plântulas, foi desidratado em estufa para posterior confecção de exsicatas. As amostras foram incorporadas sob os números MG 168.238 (Gurgel, E.S.C, 193) IAN 178.310 (Carvalho, A.C.M 90).

Os caracteres morfológicos dos frutos e sementes, do processo germinativo e das plântulas foram ilustrados com fotografias. As fotografias foram feitas em estereomicroscópio binocular Zeiss Stemi SV6, com capturador de imagem digital sound vision SV, micro adaptado e máquina fotográfica digital Nikon DIX, com lentes para ampliar e visualizar as estruturas.

\section{RESULTADOS}

\section{Morfologia do fruto}

Infrutescência na axila da folha (Figura 1b). Pedicelo herbáceo, amarelo esverdeado, opaco, apresenta raros tricomas simples, hialinos, curtos, retos e também alguns adpressos, com 6,33 \pm 19,08 $(4,24-9,63) \mathrm{cm}$ de comprimento.

$\bigcirc$ fruto é um folículo simples, carnoso (Figura 1b), a deiscência inicia-se quando o fruto começa a amadurecer, com a abertura próximo ao pedicelo, na base das valvas, as quais não apresentam torção após a deiscência (Figura 1b), placentação basal livre, monospérmico. Estenocárpico, subgloboso (Tabela 1), ápice e margem arredondados, com apículo de ca. $0,16 \mathrm{~cm}$, subestipitado, margens inteiras não constrictas. Fruto imaturo verde (Figura 1a), maduro verde amarelado. Exocarpo seco, cartáceo, opaco e glabro, amarelo quando maduro e verde quando

Tabela 1. Dimensões (cm), desvio padrão e coeficiente de variação (C.V.) dos frutos de Virola surinamensis (Rol. ex Rottb.) Warb. (n=30).

\begin{tabular}{llllll}
\hline & Máximo & Média & Mínimo & Desvio Padrão & C.V. $(\%)$ \\
Diâmetro maior & 2,99 & 2,52 & 2,32 & 0,11 & 4,51 \\
Diâmetro menor & 2,54 & 2,39 & 2,15 & 0,88 & 3,54 \\
\hline
\end{tabular}

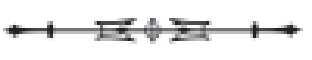


imaturo, com 0,54 mm de espessura. Mesocarpo coriáceo em tons castanhos, também opaco e glabro, com 2,52 mm de espessura. Endocarpo membranoso, em tom avermelhado devido ao arilo, 0,44 mm de espessura. Dispersão endozoocórica. Funículo curto, seco e farináceo.

\section{Morfologia da semente}

Descrição externa: estenospérmica, globosa, ápice e base achatados (Figura 1c). Com inserção basal livre. Arilo laciniado, vermelho, recobrindo toda a semente (Figura 1d). Constituída por duas camadas de tegumento, a testa, mais externa, opaca, glabra, cartácea desidratada e membranosa quando hidratada, em tons castanhos (Figura 1c). Região hilar basal, hilo orbicular, homocrômo, rafe linear, em tons castanhos, homócroma, conferindo um efeito listrado à testa da semente (Tabela 2).

Descrição interna: tégmen, situado abaixo da testa, também opaco, glabro e em tons castanhos, entretanto, mais claros que a testa, esponjoso e, quando visto sob lupa, com pontuações. Endosperma ruminado, esbranquiçado, oleoso e envolve todo o embrião. Embrião basal, rudimentar, micro e endospérmico. Cotilédones e eixo embrionário reduzidos. Plúmula imperceptível.

\section{Morfologia da germinação}

Germinação criptocotiledonar, epígea, emergência reta. Com a hidratação, a semente entumece-se, aumentando o seu volume e, em média vinte e sete dias após a semeadura, a radícula rompe o tegumento abaixo da região hilar, inicialmente cilíndrica, curta, glabra, esbranquiçada. Cinco dias depois, à medida que ocorre o seu alongamento, adquire tom castanho claro, entretanto o ápice é ferruginoso (Figura 2a), coifa inconspícua (Figura 2b). Com o coleto não evidenciado, observa-se apenas uma diferença de cor entre a radícula e o hipocótilo (Figura 2c). Hipocótilo amarelado, cilíndrico, subherbáceo, reto (Figura 2d), com muitos tricômas estrelados e simples, em tons castanhos, curtos, retos e retos com ápice curvo. Os cotilédones não são liberados dos tecidos da semente (Figura 2d).

\section{Morfologia da plântula}

Sistema radicular pivotante, raiz primária axial, cilíndrica, sinuosa, sub-herbácea, crassa, delgada,

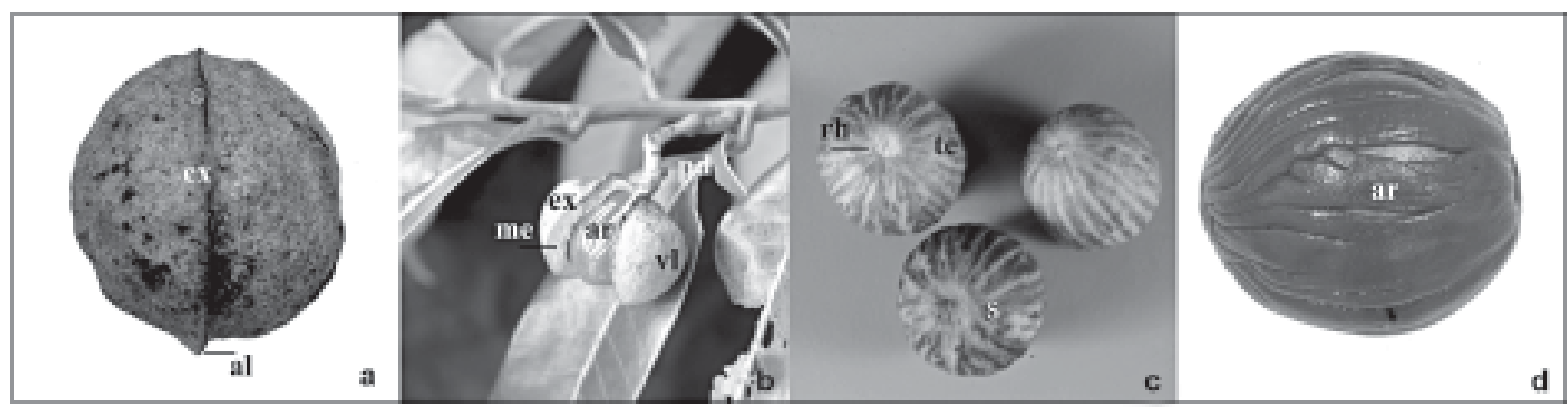

Figura 1. V. surinamensis. Detalhes do fruto: a) fruto subgloboso imaturo verde; b) folículo maduro; c) sementes globosas; d) arilo fimbriado. al-aresta longitudinal; ar-arilo; ex-exocarpo; f-fruto; me-mesocarpo; pd-pedúnculo; rh-região hilar; s-semente; te-testa; vl-valva.

Tabela 2. Dimensões (cm), desvio padrão e coeficiente de variação (C.V.) das sementes de Virola surinamensis (Rol. ex Rottb.) Warb. ( $n=30)$.

\begin{tabular}{llllll}
\hline & Máximo & Média & Mínimo & Desvio Padrão & C.V. $(\%)$ \\
Diâmetro maior & 16,26 & 14,17 & 13,26 & 0,83 & 5,83 \\
Diâmetro menor & 15,72 & 14,14 & 13,09 & 0,66 & 4,63 \\
\hline
\end{tabular}

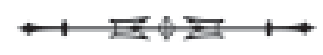




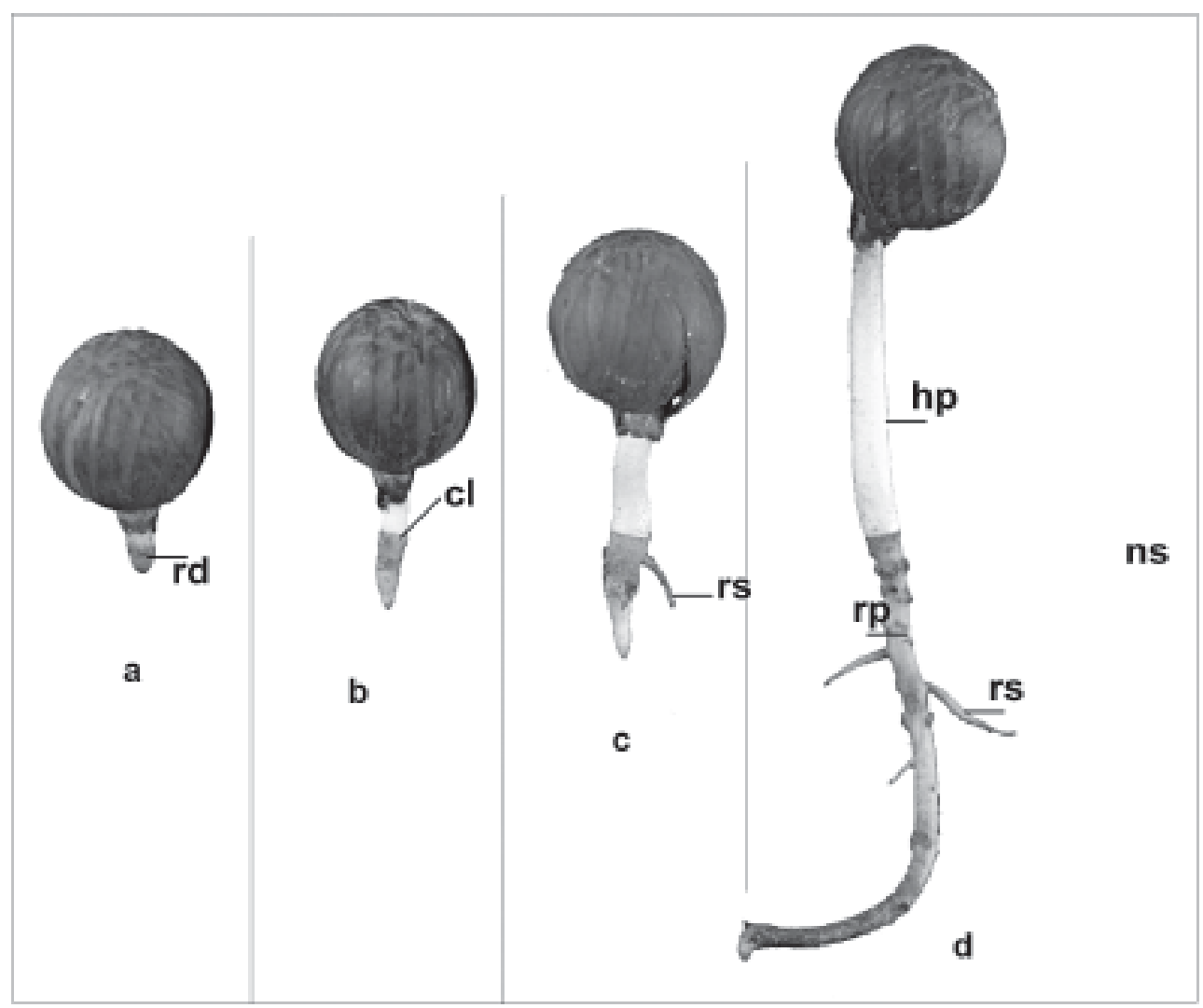

Figura 2. V. surinamensis. Detalhes do processo germinativo: a) emissão da radícula (32 dias após a semeadura); b) radícula alongada (35 dias após a semeadura); c) raízes secundárias (37 dias após a semeadura); d) raiz principal alongada com raízes laterais (40 dias após a semeadura). c-coleto; hp-hipocótilo; ns-nível do solo; rd-radícula; rp-raiz primária; rs-raiz secundária; tg-tegumento.

glabra, mais espessa na base e afilada no ápice, as raízes secundárias não concorrem com a principal em comprimento, formando um conjunto irregular castanho claro; raízes secundárias não-ramificadas e também glabras (Figura 3a). Coleto não evidente, perceptível apenas uma diferença de cor entre o hipocótilo e a raiz primária, castanho-claro esverdeado. Esta região de transição apresenta raros tricomas simples, hialinos, curtos, retos e também adpressos. Observam-se, ainda, estrias longitudinais em tons castanhos. Hipocótilo epígeo, reto, longo, delgado, cilíndrico, sub-herbáceo, ápice verdeesbranquiçado e mais espesso, região basal (próximo ao coleto) amarelada; superfície hirsuta, com poucos tricomas estrelados e simples, hialinos e castanhos, curtos e retos com ápice curvo. Cotilédones envolvidos pelo endosperma ruminado e pelos tecidos tegumentares da semente, localizados no ápice do hipocótilo (Figura 3c) e inseridos no nó cotiledonar, no qual se observa apenas o longo pecíolo acanalado, verde, com superfície hirsuta pela presença de tricomas semelhantes aos que ocorrem no hipocótilo. Epicótilo cilíndrico, longo, reto, delgado, sub-herbáceo, verde com tricomas semelhantes aos do hipocótilo, presença de pontuações arredondadas e castanhas próximas ao cotilédone. Quarenta e sete dias após a semeadura, observa-se a plântula formada com eófilos simples (Figura 3a), alternos, verdes, discolores, face adaxial mais escura que a abaxial (Figura 3 b), prefolheação

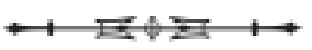




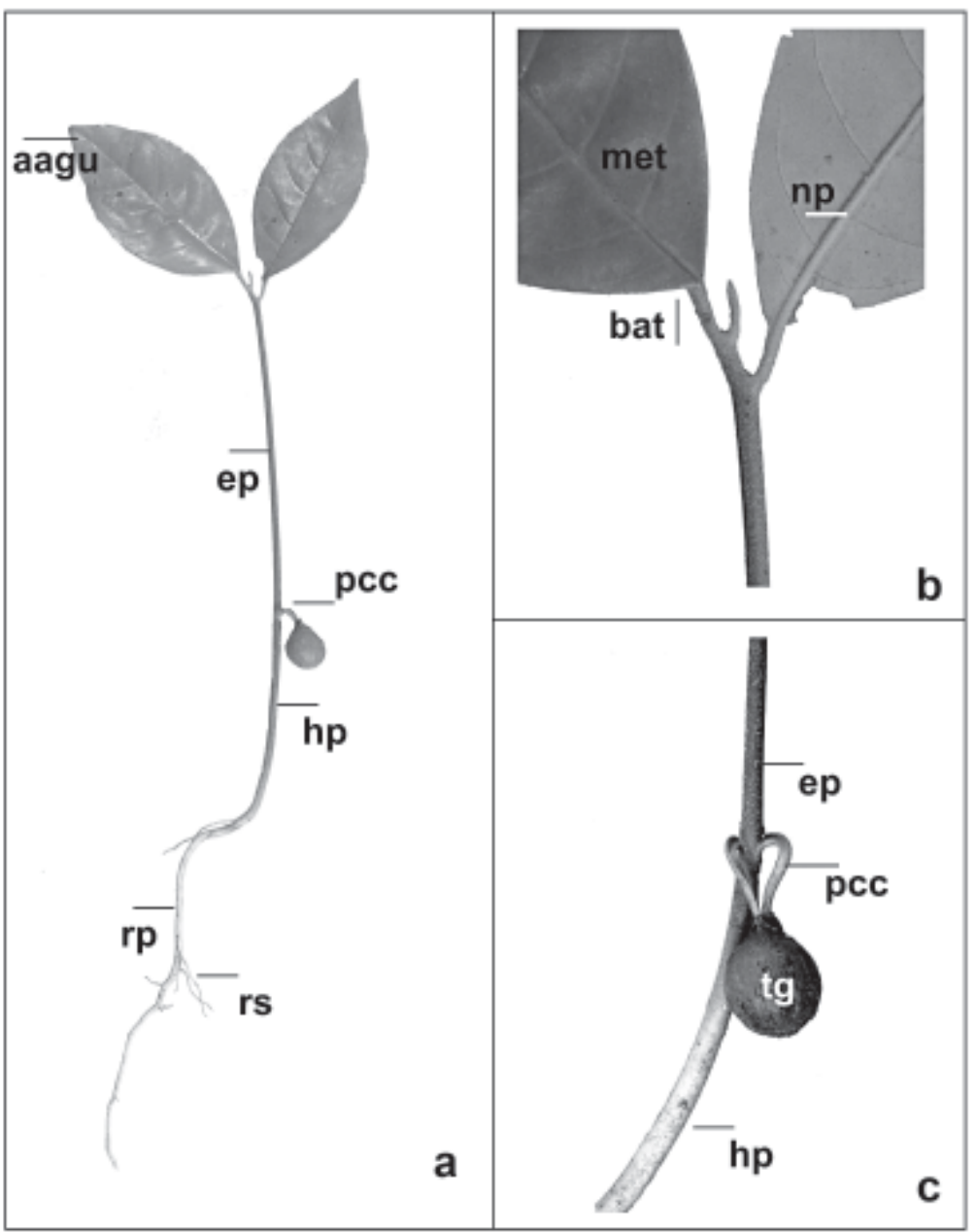

Figura 3. V. surinamensis. Detalhes da plântula: a) hábito (47 dias após a semeadura); b) eófilos simples ; c) criptocotilédones. aagu-ápice agudo; bat-base atenuada; ep-epicótilo; hp-hipocótilo; met-metáfilo; np-nervura pricipal; pcc-pecíolo cotiledonar, rp-raiz principal; rsraiz principal; tg-tegumento

valvar. São encontrados tricomas simples, hialinos e ferruginosos, curtos e longos, retos e adpressos na margem e na nervura principal em ambas as faces, nervação broquidódroma, com nervuras imersas na face adaxial e impressas na face abaxial, elíptico, ápice agudo, margem inteira e ciliada com tricomas simples, hialinos, curtos e longos, base atenuada. Pecíolos curtos, canaliculados, verdes, delgados, coberto por tricomas semelhantes aos presentes no hipocótilo. Pulvinos ausentes (Figura 4).

\section{DISCUSSÃO}

Segundo Rodrigues (1980), a infrutescência de $V$. surinamensis é essencialmente glabra por inteiro, com 3 a 8 frutos maduros por infrutescência, pedicelados (pedicelos grosos de 3 a $7 \mathrm{~mm}$ de comprimento), ovóides ou subglobosos, 13 a $21 \mathrm{~mm}$ de comprimento, 11 a $18 \mathrm{~mm}$ de largura apiculado no ápice, levemente estipitados na base, ligeira ou distintamente carinados e pericarpo de

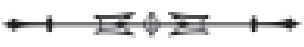




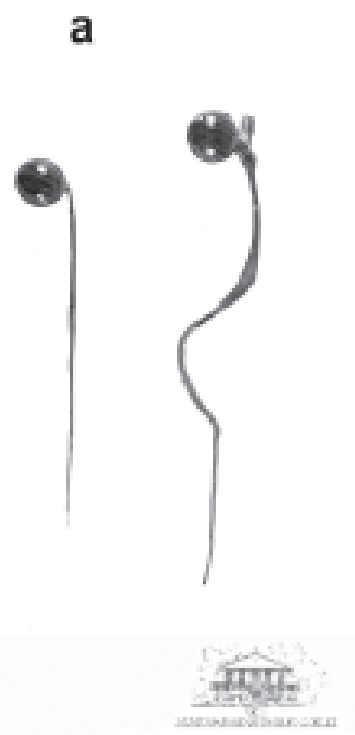

Herbirie MGG - Balken Para Brasil

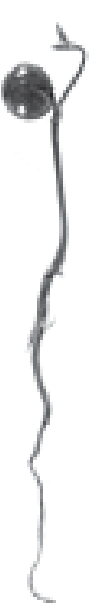

MYRISTCACEAE

MG 16028

Matis: MG 168267

Plinhle: 04

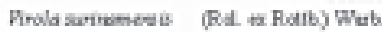

Nont water: woinh

Desrainuds: Cuenths A C M

Bredi, Pard, Beke, Enebrepa Amazisla Orkwial/

Wherateia de Batanice

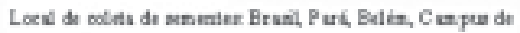

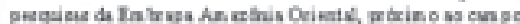

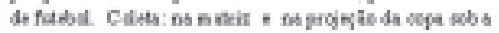

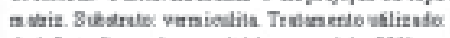

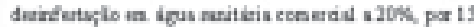

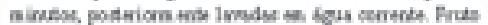

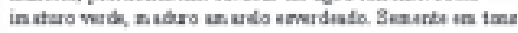

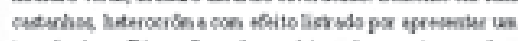

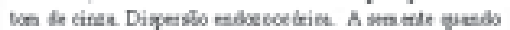

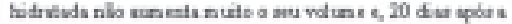

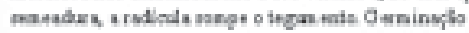

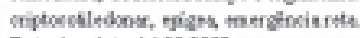

Dete de edete 1402.2000

Data de mesio 1602 2002.

Eeiente da radiods at aj 2302

Gergel E. S.C. 193

20 Abrial 2000

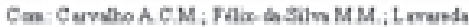

R.H.R; T doth P.S

Dupl 1 Wa, MO

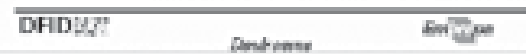
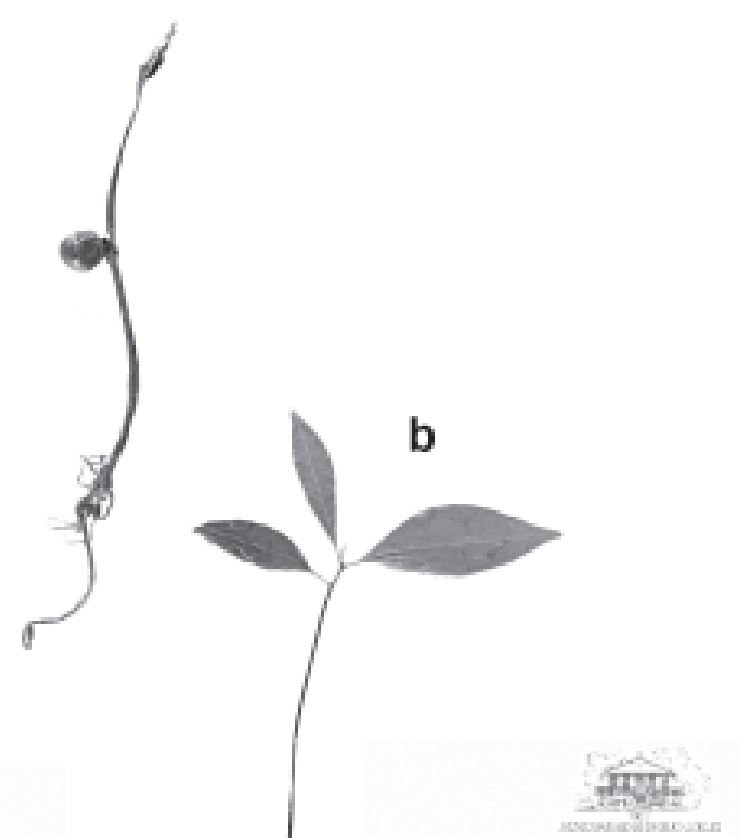

Herbkio MG - Belim.Pab-Brail

MYeAsticacese

MG 1022\%

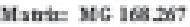
Fanhala: 04

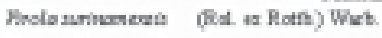

Bene vilger: wevite

Deterninuda: Cwrols A C M

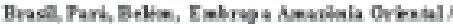

Lakerularis de Ba Gavice

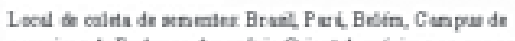

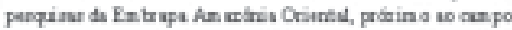

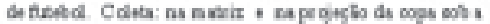

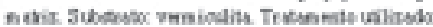

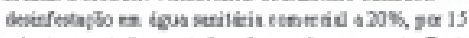

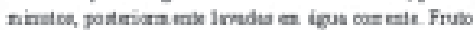

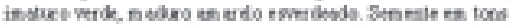

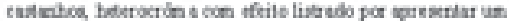

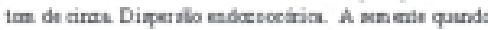

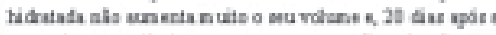

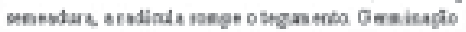

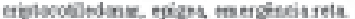

Deste edete 14022100.

Dutade anea 16.02 .2002

Eainto tarudadx at as 2362

Gurel I.S.C. 193

20 asril $2 m 2$

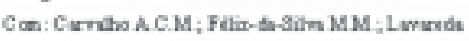
R.M. $\&: T$ Tudu $P S$.

Dual: tas, Mo

Figura 4. Virola surinamensis (Rol. ex Rottb.) Warb. Exsicata: a) processo germinativo; b) plântula. 
1 a 2 mm de espessura coriáceo. Também neste estudo observou-se frutos glabros, subglobosos, apiculados, subestipitados e carenados, entretanto, diferente do citado por Rodrigues (1980), o pericarpo é mais espesso com ca. 3,5 mm.

Para Barroso et al. (1999), o fruto de Myristicaceae é originário de um gineceu superovariado, monocarpelar, com uma ou mais sementes, aberto na maturação pela separação dos bordos carpelares e em fase adiantada de deiscência, podendo ocorrer uma progressão da fenda ventral do folículo até certo ponto, ou mesmo total, formando-se duas valvas.

Neste trabalho observou-se em $V$. surinamensis um fruto simples, unicarpelar, monospermo e carnoso, que se abre na maturação por fenda ventral, como um folículo. Essa abertura ventral continua através da parte dorsal, acabando o fruto por abrir-se em duas valvas, confirmando o citado por Barroso et al. (1999).

Van Roosmalen (1985), ao identificar estratégias de dispersão, reconheceu que espécies da família Myristicaceae apresentam frutos atraentes com uma ou poucas sementes grandes, coloridas, brilhantes, apresentando arilo ou sarcotesta, mesocarpo relativamente carnoso e rico em lipídios. Podem ser ainda cápsulas com camadas espessas, consumidas por frugivoros especialistas, como macacos e pássaros, relativamente grandes: os pássaros processam o arilo e regurgitam as sementes tratando-as suavemente dentro do trato digestivo. Segundo o mesmo autor, as sementes V. surinamensis são dispersadas por endozoocoria.

Segundo Rodrigues (1980), V. surinamensis apresenta arilo fendido quase até a base e semente levemente elipsóide. Também observou-se o mesmo tipo de arilo, entretanto, a forma da semente descrita pelo referido autor difere da forma do espécime aqui estudado, uma vez que se apresenta globosa.

A terminologia arilóide é a estabelecida para designar as estruturas carnosas formadas em torno do exostoma da micrópila e, em termos gerais, as estruturas arilóides estão relacionadas com ornitocoria. $O$ arilo verdadeiro origina-se na extremidade do funículo, junto à região do hilo, porém, é muito difícil, sem os recursos da ontogenia e anatomia, descobrir e determinar a origem dessas excrescências carnosas das sementes. Por esse motivo, é duvidoso considerar a diferença entre arilo e arilóide. Corner (1951) apresentou uma lista de família com sementes ariladas. Van der Pijl (1966 apud Barroso et al., 1999) criticou essa lista de nomes, considerando que a maioria dos exemplos dados tratavam-se de sementes providas de arilóides.

Barroso et al. (1999) citaram que as sementes das espécies pertencentes à familia Myristicaceae são basais, apresentam arilo ou arilóide franjado (fimbriado), laciniado, geralmente de colorido vivo, cobrindo mais da metade do comprimento da semente; o endosperma é crasso, com ou sem ruminação, a testa tem o estrato externo membranáceo ou carnoso; a rafe é linear, visível externamente; endosperma geralmente oleoso, via de regra ruminado; embrião diminuto, próximo do hilo.

Em V. surinamensis, o arilo é laciniado, vermelho, recobrindo toda a semente; o endosperma é crasso, oleoso e ruminado; a testa é cartácea desidratada e membranosa quando hidratada. A rafe é linear, em tons castanhos, homócroma, conferindo um efeito listrado à testa da semente; também o embrião é micro e próximo ao hilo.

A despeito de estudos sobre morfologia da plântula, foram encontrados apenas os seguintes trabalhos:

- Duke (1969), ao descrever várias famílias, entre elas Myristicaceae, analisou uma Virola sp., descreveu a germinação como criptocotiledonar epígea e citou que os eófilos são supracotiledonares, inteiros, alternos, com prefolheação conduplicada e com venação peninérvea. Ressaltou a presença de látex, indumento e um aroma diagnóstico freqüente.

- Rodrigues (1980), ao estudar a plântula de V. surinamensis, encontrou praticamente as mesmas características descritas por Duke (1969), tais como

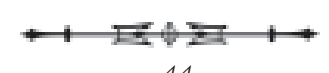


germinação criptocotiledonar epígea, cotilédones pedicelados acima do solo, envolvidos pelos tegumentos da semente até o seu desprendimento, eóflos também peciolados, supracotiledonares, simples, alternos, conduplicados, estipulados, peninérveos, inteiros, ferrugíneo-tomentosos ou glabracentes.

Neste estudo o mesmo tipo de germinação foi observado, isto é, criptocotiledonar epígea, com a presença de cotilédones pedicelados e envolvidos pelos tegumentos da semente até o seu desprendimento; os eófilos são supracotiledonares, alternos e ferrugíneo-tomentosos ou glabrescentes como os eófilos da espécie estudada por Duke (1969).

Na plântula de $V$. surinamensis, foram encontrados tricomas, algumas estruturas (pontos) semelhantes a glândulas e a presença ou não de tricomas e glândulas (DUKE, 1965) são caracteres muito importantes, para diferenciar espécies.

A presença de estípulas nas plântulas, estrutura de proteção, segundo Burkart (1952), também é uma característica relevante. Duke (1969), estudando uma espécie de Myristicaceae (Virola sp.), e Rodrigues (1980) também encontraram este caráter, mas vale ressaltar que em $V$. surinamensis não foi encontrado.

\section{CONCLUSÕES}

As ilustrações para frutos, sementes, processo germinativo e plântulas, associadas às descrições, fornecem subsídios para o reconhecimento prático da espécie aqui estudada.

A morfologia dos frutos e sementes associadas às observações das plântulas permitem fazer uma identificação segura.

A metodologia adotada no presente estudo mostrou-se eficiente.

Foram feitas descrições que permitem identificar a espécie na fase de plântula. Os principais elementos de identificação, nesta fase, foram as características dos dois primeiros metáfilos.

\section{REFERÊNCIAS}

BARROSO, G. M. et al. 1999. Frutos e sementes: morfologia aplicada à sistemática de dicotiledôneas. Viçosa: Editora UFV, Universidade Federal de Viçosa. 443 p.

BURKART, A. 1952. Las Leguminosas Argentinas sylvestres y cultivadas. Buenos Aires: acne agenc. 590 p.

CORNER, E. J. H. 1951. The leguminous seed. Phytomorphology, V. 1, p. 117-150.

DUKE, J. A. 1965. Keys for the identification of seedlings of some proeminent woody species in eight forest types in Puerto Rico. Ann. Missouri Bot. Gard., v. 52, n. 3, p. 314-350.

DUKE, J. A. 1969. On tropical tree seedlings, systems and systematics. Ann. Missouri Bot. Gard., v. 56, n. 2, p. 135-161.

DUKE, J. A.; POLHILL, R. M. 1981. Seedlings of Leguminosae. In: POLHILL, R. M.; RAVEN, P. H. (Ed.). Advances in Legumes Systematics. England: Royal Bot. Garden, Kew Richmond, Surrey. p. $941-949$. v. 2.

FERREIRA, R. A. 1997. Caracterização morfológica de frutos, sementes, plântulas e mudas de espécies arbóreas do cerrado de Minas Gerais. 109 f. Dissertação (Mestrado) Universidade Federal de Lavras.

FONT-QUER, P. 1963. Dicionário de Botânica. Barcelona: Labor. $1244 \mathrm{p}$.

GURGEL, E. S. C. 2000. Morfologia de frutos, sementes, germinação e plântulas de leguminosas presentes em uma vegetação de mata secundária na Amazônia Central. Dissertação (Mestrado) - Instituto Nacional de Pesquisas da Amazônia, Universidade do Amazonas, Manaus, Amazonas. 160 p.

KUNIYOSHI, Y. S. 1983. Morfologia da semente e da germinação de 25 espécies arbóreas de uma floresta com araucária. 232 f. Dissertação (Mestrado) - Universidade Federal do Paraná, Curitiba, Paraná.

LAWRENCE, G. H. M. 1970. Taxonomy of vascular plants New York: The Macmillan Press. 823 p.

LORENZI, H. 1992. Árvores brasileiras: manual de identificação e cultivo de plantas arbóreas nativas do Brasil. Nova Odessa, SP: Editora Plantarum Ltda. 352 p.

MARTIN, A. C. 1946. The comparative internal morphology of seeds. Am. Midl. Nat., v. 36, n. 3, p. 513-660.

OLIVEIRA, E. C. 1993. Morfologia de plântulas florestais. In: AGUIAR, I. B.; PIÑA-RODRIGUES, F. C. M.; FIGLIOLA, M. B. (Ed.). Sementes florestais tropicais. Brasília: ABRATES. p. 175-214.

RADFORD, A. E. et al. 1974. Vascular plants systematics. New York: Harper and Row. 877 p.

RIBEIRO, J. E. L. S. et al. 1999. Flora da reserva Ducke: guia de identificação de plantas vasculares de uma floresta de terra-firme na Amazônia Central. Manaus: INPA. 816 p.

RODERJAN, C. V. 1983. Morfologia do estádio juvenil de 24 espécies arbóreas de uma floresta com araucária. $148 \mathrm{f}$. Dissertação (Mestrado) - Universidade Federal do Paraná, Curitiba, Paraná. RODRIGUES, W. A. 1972. A ucuúba da várzea e suas aplicações. Acta Amazonica, v. 2, n. 2, p. 29-47.

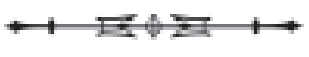


RODRIGUES, W. A. 1980. Revisão taxonômica das espécies de Virola Aublet (Myristicaceae) do Brasil. Acta Amazonica, v. 10, n. 1, suplemento, 127.

STERN, W. T. 1992. Botanical latin: history, grammar, syntax, terminology and vocabulary. New York: Ed. Hafner Publishing Company. 566 p.

STUESSY, F. T. 1989. Plant taxonomy the systematic evaluation of comparative data. New York: Columbia University Press. p. 217-233. SYSTEMATICS ASSOCIATION COMMITTEE FOR DESCRIPTIVE TERMINOLOGY. 1962. Terminology of simple symmetrical plane shapes (chart 1). [S.1.:s.n.]. p. 104-109. (Taxon, 9).
VAN DER PIJL, L. 1966. Ecological aspects of fruit evolution. Proceedings Nederlandse Akademie van Wetnschappen, Amsterdam, v. 69, p. 597-640.

VAN DER PIJL, L. 1982. Principles of dispersal in higher plants. 3. ed. Berlin: Springer Verlag. 162 p.

VAN ROOSMALEN, M. G. M. 1985. Fruits of the Guianan Flora. Neetherlands: Utretcht Institute of Systematic Botany, Utretcht University. 483 p. 